\title{
PIONEIROS DO MARXISMO E DA ESCOLA NOVA NO BRASIL: O LUGAR DA ESCOLA NO PROCESSO HISTÓRICO
}

\author{
MARXIST AND NEW SCHOOL INTRODUCERS IN BRAZIL: the school place in \\ the historical process \\ PIONEROS DEL MARXISMO Y DE LA ESCOLA NOVA EN EL BRASIL: el lugar de
la escuela en el proceso histórico
}

Aparecida Favoreto

Professora doutora do Curso de Pedagogia e do Mestrado em Educação da Universidade Estadual do Oeste do Paraná (UNIOESTE).

cidafavoreto@globo.com

\begin{abstract}
RESUMO: O artigo analisa a proposta educacional dos pioneiros da Escola Nova e a dos pioneiros do pensamento marxista no Brasil. Os escolanovistas partiam do pressuposto de que a educação era um elemento ativo no processo de transformação social, sendo assim, elaboraram um projeto amplo de reforma na política educacional, na estrutura do ensino e na pedagogia. Para os pioneiros marxistas, o elemento ativo estaria no desenvolvimento histórico e na mobilização de classe e não na escola. Assim, priorizou a formação do militante revolucionário. Em termos escolares, seguiram juntos com os escolanovistas, acreditando ser a escola burguesa uma etapa necessária. Uma postura que encontra respaldo na concepção etapista da história que fundamentava a luta marxista do período.
\end{abstract}

PALAVRAS-CHAVE: Pecebistas. Escolanovistas. Escola e transformação social.

ABSTRACT: The article analyzes the educational proposal of the pioneers of the New School and the pioneers of Marxist thought in Brazil. The New School researchers have assumed that education was an active element in the process of social transformation. Therefore, they developed a great reform project in education policy, education structure as well as in its pedagogy. For the Marxist pioneers, the active element would be placed in the historical development and the mobilization of class, but not in the school. Like this, it prioritized the training of the revolutionary militant. In school terms, both of them followed along with the New School introducers, since they believed that the bourgeois school was a necessary step. It is an attitude supported by the step by step conception of history that the Marxist struggle was based during that period.

KEYWORDS: New School and Marxist Introducers. School and social transformation.

RESUMEN: El artículo analiza a la propuesta educacional de los pioneros de la Escola Nova a la de los pioneros del pensamiento marxista en el Brasil. Los escolanovistas partian del presupuesto de que la educación era un elemento activo en el proceso de transformación social, frente a eso, desarollaran un proyecto amplio de reforma en la política educacional, en la estructura de la enseñanza y en la pedagogia. Para los pioneros marxistas, el elemnto activo estaria en el desarollo histórico y en la mobilización de la clase y no en la escuela. De esa manera, priorizó la formación del militante revolucionário. En termos escolares, siguieron juntos com los escolanovistas, creendo que la escuela burguesa era una etapa necesária. Una postura que encontra apoyo en la concepción etapista de la historia que fundamentaba la lucha marxista del periodo.

PALABRAS CLAVE: Pecebistas. Escolanovistas. Escuela y Transformación social. 
PIONEIROS DO MARXISMO | Aparecida Favoreto

\section{1 | INTRODUÇÃO}

O debate em torno de explicações e de soluções para os problemas educacionais é recorrente na história da educação brasileira. Fazendo um breve retrocesso, observa-se que durante todo o século $X X$, marxistas e liberais ${ }^{1}$ foram os que mais se enfrentaram, apontando perspectivas diversas sobre a eficiência, os objetivos e a função da escola no processo de mudança na e/ou transformação da sociedade ${ }^{2}$.

É importante que se diga que as duas correntes teóricas citadas geraram inúmeras análises sobre a história da educação brasileira, as quais, em um amplo leque de argumentações, não deixaram de apontar qual seria o papel da escola no processo histórico. Sem condições de dar conta de toda a discussão sobre a questão, no limite desse texto, apenas recupera o debate educacional da década de 1930 e verifica como cada corrente se posicionou perante a defesa da escola pública. Esse interesse surgiu ao observar que, entre as análises marxistas atuais, sobressai a tese de que, na década de 1930, houve uma luta entre interesses da burguesia e da classe trabalhadora. Com base nesse pressuposto, alguns teóricos ${ }^{3}$ afirmam que os escolanovistas, adeptos dos princípios liberais, ao formularem seu projeto educacional, contribuíram para recompor e fortalecer a hegemonia burguesa. Isso colaborou para desmobilizar a proposta pedagógica advinda das classes populares, a qual seria realmente democrática e revolucionária. Entretanto, ao reler os documentos da época, verifica-se que o suposto embate entre diferentes projetos educacionais merece outros estudos.

Nesse sentido, nesse artigo objetiva-se recuperar os discursos dos pioneiros da Escola Nova e os dos pioneiros do pensamento marxista brasileiro, verificando se eles divergiam quanto ao projeto educacional daquele período. Neste interesse, destacam-se quais eram as expectativas educacionais de cada corrente, buscando identificar suas perspectivas em relação à escola, na luta por transformações na e da sociedade. Assim, são levantados, no trabalho ora apresentado, alguns elementos para refletir sobre a relação entre perspectivas educacionais e concepção de história, fornecendo-se alguns dados para pensar a produção historiográfica marxista brasileira.

Para apreender a concepção de educação escolar presente no pensamento escolanovista brasileiro, utiliza-se como fonte principal o Manifesto dos Pioneiros da Escola Nova de 1932. Quanto aos pioneiros do pensamento marxista brasileiro, as fontes são os documentos do Partido Comunista Brasileiro (PCB), produzidos nas décadas de 1920 e 1930 bem como as obras escritas pelos dirigentes e integrantes do partido, publicadas na época, pela imprensa vinculada ao partido e as memórias publicadas posteriormente, por outras instituições ${ }^{4}$.

\footnotetext{
${ }^{1}$ Atualmente, em virtude do desmantelamento do "socialismo real", da reestruturação da produção e da comunicação, o leque teórico tem sido cada vez mais amplo, dentre os quais, fortaleceu a teoria de que vivemos em uma nova era, em que o pensamento moderno e o marxista, em razão de buscarem uma estrutura padrão para o desenvolvimento social, não proporcionam uma leitura condizente com a realidade social. Assim, prolifera a ideia de que o mundo está aberto a opções construídas e reconstruídas a partir da identidade cultural e do sentir do indivíduo.

${ }^{2}$ Os termos mudança na e/ou transformação da sociedade são usados aqui no sentido de diferenciar o grau de alteração social. Mudança na - limita-se a mudar elementos pontuais e preservar a estrutura social. Assim, não implica rompimento, mas apenas inovação, reforma ou modernização, o que significa conservação. Transformação da - entende-se um rompimento radical com a estrutura anterior, assim, não se restringe a elementos pontuais, a uma área geográfica e nem se faz em curto prazo. Trata-se de profundas transformações do sistema sócioeconômico, político, jurídico-constitucional, com consequências na forma de o homem pensar, agir e se relacionar, ou seja, revolução.

${ }^{3}$ Sobre esta luta ideológica no projeto educacional brasileiro consultar: Saviani (1983); Ghiraldelli Júnior (1989); Gandini (1980); Warde (1984); Ribeiro (1998); Saes (2005).

${ }^{4}$ Sobre as fontes, destaca-se que muitas foram colhidas graças ao trabalho de historiadores que, vinculados às instituições universitárias ou semelhantes, fizeram a coleta, a organização e a publicação de alguns documentos.
} 


\section{2 | A DÉCADA DE 1930: O PROJETO ESCOLANOVISTA}

No que se refere à década de 1930, é necessário grifar que, a exemplo do que ocorria em diversos países da América e da Europa ${ }^{5}$, o Brasil vivia um momento de reorganização política, econômica e de produção ${ }^{6}$, que repercutia sobre o debate educacional.

Naquele período, o debate educacional brasileiro se intensificou, e assim, cresceram as defesas de formação geral e técnica, condizentes com o desenvolvimento da industrialização e da democracia. Defendia-se também, a construção de uma política nacional de educação, a qual, além de integrar todas as regiões em um único sistema de ensino, possibilitasse a efetivação da educação pública e gratuita. Desse debate, vários setores da sociedade se posicionaram. Aliás, tal período foi marcado por reformas educacionais realizadas em alguns Estados da União ${ }^{7}$, um processo que ganhou maior vigor com a criação da Associação Brasileira de Educação (ABE) em 1924, a qual promoveu diversas Conferências Nacionais de Educação, que registraram importantes contribuições sobre o debate escolar e políticas educacionais. Entre as discussões levantadas, sem dúvida, a mais importante delas foi sobre a organização do Sistema Nacional de Educação, a qual repercutiu na produção do Manifesto dos Pioneiros da Educação Nova: a reconstrução educacional no Brasil em $1932^{8}$.

O Manifesto de 1932 caracteriza-se pela defesa de alguns princípios básicos, como: gratuidade, obrigatoriedade, laicidade, coeducação, complementados com a defesa de uma ampla reforma pedagógica e da construção de um sistema nacional de educação. É importante que se diga que, paralelo a cada defesa, o documento também registra severa crítica ao passado educacional brasileiro ${ }^{8}$.

\footnotetext{
${ }^{5} \mathrm{Na}$ década de 1930, o mundo ainda ressentia os efeitos da Primeira Guerra Mundial e vivia o clima de uma segunda; sofria os efeitos da queda da bolsa de Nova York, enquanto o regime soviético apontava uma nova possibilidade de organização e gestão econômica. Nesse contexto, em meio ao crescimento do uso do automóvel, do telefone, do rádio e dos medicamentos, fortalecem as crenças nos poderes da ciência, do Estado intervencionista e do trabalho racional.

${ }^{6}$ No Brasil, esse período é marcado pela crise da economia cafeeira, fim da "política café com leite", constituição do Estado Novo, imigração e crescimento urbano/industrial. Também é marcado por movimentos sociais que mostram descontentamento com os modelos político e econômico predominantes, dentre os quais se destacam os movimentos tenentistas, a Semana de Arte Moderna e os movimentos dos trabalhadores, com relevo à rebelião comunista de 1935.

${ }^{7}$ Entre os Estados que efetuaram alguma reforma em seu sistema de ensino, encontram-se: São Paulo, por Sampaio Dória (1920); Ceará, por Lourenço Filho (1922); Distrito Federal, por Carneiro Leão (1922); Bahia, por Anísio Teixeira (1924); Rio Grande do Norte, por Bezerra de Menezes (1925); Paraná, por Lisímaco da Costa (1927).

${ }^{8}$ O Manifesto dos pioneiros da Escola Nova de 1932, que aqui denominamos como Manifesto de 1932, originou-se da IV Conferência Nacional de Educação (1931), em que, Getúlio Vargas e Francisco Campos (Ministro do recémcriado Ministério da Educação) estiveram presentes e, na solenidade de abertura, solicitaram que os conferencistas colaborassem com o governo provisório na definição da sua política educacional. Sem atingir uma unidade teórica e ideológica na Conferência, alguns intelectuais, com destaque para Fernando de Azevedo e Anízio Teixeira, redigiram o Manifesto de 1932, o qual, além de seus principais redatores, contou com os seguintes signatários: Afrânio Peixoto, A. de Sampaio Dória, Manoel B. Lourenço Filho, Roquette Pinto, J. G. Frota Pessoa, Julio de Mesquita Filho, Raul Briquet, Mario Casssanta, Carlos Delgado de Carvalho, Antonio F. de Almeida Jr., J. P. Fontenelle, Roldão Lopes de Barros, Noemy M. da Silveira, Hermes Lima, Attilio Vivacqua, Francisco Venâncio Filho, Paulo Maranhão, Cecília Meirelles, Edgar Sussekind de Mendonça, Armanda Álvaro Alberto, Garcia de Rezende, Nóbrega da Cunha, Paschoal Leme e Raul Gomes. A propósito dos signatários, destaca-se que entre eles não havia consenso sobre as perspectivas sociais, pois, junto com os liberais, haviam simpatizantes do PCB, tal como Paschoal Leme, bem como havia uma divergência entre Anísio Teixeira e Fernando de Azevedo sobre a questão da igualdade social.
} 
No que se referem às políticas governamentais, no documento, seus redatores registraram que no Brasil não havia planejamento, logo, prevaleciam muita confusão e a obscuridade. Ao mesmo tempo destacaram que as poucas iniciativas tinham sido "parciais", "arbitrárias", "sem espírito de continuidade [...] lançadas sem solidez econômica e sem visão global do problema" (MANIFESTO, 1960, p. 108). Também assinalaram que o modelo de educação vigente era elitista, visto que não garantia a permanência dos economicamente desprivilegiados. Neste aspecto, defenderam que um novo modelo deveria ser constituído, o qual não poderia "servir aos interesses de classes, mas aos interesses do indivíduo" (MANIFESTO, 1960, p. 112). Nessa perspectiva, combateram o dualismo entre o ensino cultural e o profissional e destacaram que o Estado deveria tornar a escola acessível a todos e em todos os seus graus, a partir da criação de possibilidades iguais para que todos os cidadãos pudessem desenvolver, ao máximo, suas aptidões naturais. Enfatizaram ainda, que era necessário criar um mecanismo interno que permitisse o fluxo dos alunos, defendendo assim, a declaração de diretrizes nacionais.

No aspecto político, o Manifesto de 1932 se caracteriza pela defesa de uma reforma organizacional, que pudesse garantir uma unidade nacional no planejamento, no currículo, na formação do espírito e na ascensão de todos à escola.

A defesa de reajuste também se direciona aos aspectos pedagógicos, em que, sobressai a defesa de um novo método de ensino (observação, pesquisa e experiência). O propósito era substituir o conceito entendido como estático de educação por um dinâmico, de modo que, com a aquisição ativa do conhecimento pudesse desenvolver a personalidade integral do aluno ${ }^{9}$, tornando-o mais participativo, investigativo e criativo. Assim, o Manifesto de 1932 lançou criticas ao modelo pedagógico da época, afirmando que ele não considerava o fator psicológico do interesse e destacou que ele se constituía por esforços inúteis de repetição. Igualmente, afirmou que a formação vigente era marcada por um conteúdo excessivamente literário, artificial, verbalista, de cunho religioso e distante da vida ativa do aluno ${ }^{10}$.

Os formuladores do Manifesto de 1932 entendiam a educação como elemento social e nessa perspectiva, registraram que a educação escolar se modifica conforme muda a sociedade. Nesse aspecto, destacaram que o mundo naquele momento passava por mudanças, em que a industrialização e a democracia se consolidavam como forma mais "desenvolvida" de organização social. Com base nessa assertiva, afirmaram que o Brasil estava "atrasado"11. Nessa perspectiva, defendiam então, a reforma educacional como uma possibilidade do País alavancar no processo de modernização. Desta forma, logo no início do documento, escreveram que a reforma educacional era mais urgente e mais eficiente do que uma reforma econômica, como se observa em:

Na hierarquia dos problemas nacionais, nenhum sobreleva em importância e gravidade ao da educação. Nem mesmo os de caráter econômico lhe podem disputar a primazia nos planos de reconstrução nacional. Pois, se a evolução orgânica do sistema cultural

\footnotetext{
${ }^{9}$ Essa perspectiva tem como pressuposto teórico Dewey e Durkheim, neste aspecto, em oposição à chamada escola tradicional, buscavam integrar escola e vida e, consequentemente, integrar o indivíduo à sociedade. Sendo assim, diferencia-se do pressuposto marxista atual que, em oposição à alienação e divisão capitalista, defende a formação do homem integral e/ou omnilateral.

${ }^{10}$ Só para esclarecer, destaca-se que o movimento educacional da década de 1930, também contou com a presença dos intelectuais católicos, os quais defenderam a continuidade do ensino religioso nas escolas.

${ }^{11}$ No período, era grande o número de registros que se referiam ao Brasil como atrasado. Uma definição que se sustentava na comparação com os países que haviam desenvolvido sua indústria e seu regime democrático. Quanto ao Brasil, afirmavam que aqui permanecia a hegemonia política de uma aristocracia rural, uma produção agrícola pouco rentável e uma cultura popular presa nas superstições e no pensamento messiânico.
} 
de um país depende de suas condições econômicas, é impossível desenvolver as forças econômicas ou de produção, sem o preparo intensivo das forças culturais e o desenvolvimento das aptidões à invenção e à iniciativa que são os fatores fundamentais do acréscimo de riqueza de uma sociedade. (MANIFESTO, 1960, p. 108).

Verifica-se assim, que para os escolanovistas, a reforma educacional poderia resolver todos os problemas do País, inclusive o da produção econômica e o da miséria. Eles compreendiam que a sociedade era um todo dinâmico, onde, uma vez fosse desenvolvido um bom sistema de ensino, o processo de modernização seria impulsionado e haveria maior riqueza para todos. Postulavam que a divulgação adequada da ciência traria benefício social, pois teria maior produção de riqueza, maior conforto e igualdade social. Defendiam assim, a reforma educacional como a alternativa mais urgente e a mais segura para conduzir o País para dias melhores, onde todos, sem distinção de classe, ganhariam. Apoiados nas ideias de Dewey (1959) ${ }^{13}$ e Durkheim (2012) ${ }^{14}$, eles acreditavam que a educação poderia corrigir os males presentes na situação econômica e adequar o Brasil à ordem de desenvolvimento que ocorria nos países mais desenvolvidos.

Em uma perspectiva positiva, quanto ao benefício da ciência, voltaram seus olhares para as divulgações científicas e para o desenvolvimento da industrialização que ocorriam na Europa e nos EUA e, acreditavam que o Brasil, sem hesitar, deveria acompanhar esse processo. Entendiam, o momento como decisivo e crítico, pois, caso o Brasil não acompanhasse o processo, poderia permanecer para sempre no atraso. Assim, destacavam que era "cada vez mais viva" a "necessidade" de se preparar para "enfrentar com o evangelho da nova geração, a complexidade trágica dos problemas postos pela sociedade moderna" (MANIFESTO, 1960, p. 126).

Nesse sentido, a "consciência" teria papel importante no processo iniciado de mudança na sociedade. Assim, defendiam que tal consciência deveria formar-se em "princípios fixos e inabaláveis", regulando, "de modo firme, todos os nossos pensamentos e ações", de maneira a formar um novo "caráter"15 (MANIFESTO, 1960, p. 126).

Nesse caso, os educadores escolanovistas apontavam uma diferença entre instruir e educar ${ }^{16}$. Desta forma, argumentavam que a escola deveria educar, de modo a preparar o povo brasileiro

\footnotetext{
${ }^{12}$ Como forma de esclarecimento, destaca-se que o pensamento escolanovista acreditava que a ciência contribuiria com a maior produção de riqueza, sendo isto, um benefício social, sem distinção de classe. Entretanto, Marx, em sua análise sobre a relação entre capital e trabalho, registrou que a ciência produz maior riqueza, mas, sob o julgo da propriedade privada, esta riqueza é apropriada pelos donos do capital, enquanto a classe trabalhadora perde força de troca, visto que é expropriada do saber e do trabalho.

${ }^{13}$ Dewey, em Democracia e educação (1959) afirmou que a educação, por intermédio de um método eficaz, poderia desenvolver no imaturo a compreensão dos meios e a identidade com os fins sociais. Assim, destacou que pela atividade orientada, conseguiria dirigir e guiar os interesses intelectuais dos alunos para atividades em conjunto, nas quais, com base nas experiências acumuladas, todos envolvidos, encontrariam um resultado comum para os problemas.

${ }^{14}$ Para Durkheim (2012, p. 110), a educação, desde que baseada em princípios científicos, seria capaz de desenvolver no indivíduo as potencialidades que a sociedade necessitava, criando assim, um "novo ser no homem". Para ele, a educação seria o principal meio que a sociedade renova a homogeneidade social, uma das condições essenciais de sua existência. Também, pela educação garantiria a formação especializada, adequando cada um para cumprir sua função, de acordo com as necessidades sociais.

${ }^{15} \mathrm{O}$ novo caráter trata-se de um novo espírito que, para eles, refere-se ao espírito científico e de cooperação.

${ }^{16}$ Para os escolanovistas, instruir limitava-se a transmissão de conhecimentos formais, os quais deveriam ser repetidos pela criança. No que se refere à educação, ampliavam seu significado, afirmando que mais do que repetir conteúdo, a escola deveria preparar o aluno para conhecer e agir no seu meio, fazendo-o progredir junto com as civilizações mais modernas. Assim, a escola criaria um novo homem.
} 
para a nova ordem da sociedade. Confiavam que, desde que a pedagogia se desenvolvesse pela experiência científica, maior seria a possibilidade de se ter um indivíduo mais curioso, ativo, participativo, solidário e com identidade nacional. Assim, esperavam que o sistema de ensino brasileiro, criteriosamente organizado e orientado, poderia ser um poderoso fator de mudança na sociedade. Nesse sentido:

[...] as únicas revoluções fecundas são as que se fazem ou se consolidam pela educação, e é só pela educação que a doutrina democrática, utilizada como um princípio de desagregação moral e de indisciplina, poderá transformar-se numa fonte de esforço moral, de energia criadora, de solidariedade social e de espírito de cooperação. (MANIFESTO, 1960, p. 126).

Verifica-se, assim, que os escolanovistas partiam do pressuposto de que a escola era o elemento agregador de forças, que poderia ser ativo no processo de mudança social. Entretanto, é necessário grifar que tais mudanças não se fariam a partir do nada, mas acompanhariam o desenvolvimento tecnológico, científico e democrático que já ocorria nas nações mais "desenvolvidas".

Diante do contexto histórico brasileiro, que se caracterizava pelo êxodo rural, imigração, crise da economia cafeeira e necessidade de desenvolver a indústria, os escolanovistas acreditavam que o ensino da ciência e a disseminação do compromisso nacional poderiam tirar o Brasil do "atraso". Para isso, defendiam que a educação deveria corresponder à vida ${ }^{17}$, de modo a ensinar o aluno "aprender a aprender". Para eles, a escola, com sua bagagem de conhecimentos e os mais diversos instrumentos pedagógicos, poderia despertar o apreço por uma vida saudável, o amor ao trabalho, à criatividade, autonomia e responsabilidade política.

\section{3 | PIONEIROS MARXISTAS: A ESCOLA BURGUESA COMO UMA ETAPA NECESSÁRIA}

No que se referem aos marxistas, é necessário grifar que tal pensamento chega ao Brasil pelo viés da atividade política revolucionária e atua de forma mais consistente após a Revolução Russa de 1917. Naquele momento, ainda em debate com a liderança anarquista, sob as orientações da III Internacional Comunista, os militantes comunistas brasileiros dispunham organizar e unificar a luta operária em um partido de classe, para conquistar o poder e, consequentemente, transformar a política e a economia da sociedade capitalista em comunista. Com esses objetivos, em 1922, foi criado o PCB ${ }^{18}$, o qual, de forma legal ou ilegal, participou das discussões políticas por intermédio de ações junto aos trabalhadores, publicação de panfletos, jornais, livros e, quando a censura permitia, o partido disputou mandatos políticos.

Ao se fazer uma leitura dos documentos oficiais da primeira fase do $\mathrm{PCB}^{19}$, observa-se que a discussão era concentrada no debate sobre a economia brasileira, o imperialismo e a forma de organizar o movimento operário. No que se refere à educação, nas poucas vezes em que se referiu, deu preferência à educação militante. Os membros do Partido, aspirando chegar o tempo de realizar a revolução operária, acreditavam que, com a divulgação das ideias comunistas entre a

\footnotetext{
${ }^{17}$ Essa perspectiva é baseada em Dewey, o qual destaca que a educação é vida, ou seja, é ativa, está em constante movimento e em processo de se refazer.

${ }^{18}$ O Partido Comunista aqui referido é o de tendência soviética criado em 1922 com a denominação de Partido Comunista do Brasil (PCB). Em 1956, adota o nome de Partido Comunista Brasileiro, mantendo a sigla PCB. Na década de 1960, sofreu uma cisão; surgiu assim o Partido Comunista do Brasil, com a sigla PC do B.

${ }^{19}$ A primeira fase do PCB aqui mencionada refere-se de 1922 a 1935.
} 
classe trabalhadora, a revolução não demoraria a acontecer. Assim, se lançaram na tarefa militante, com muito esforço, dedicação, disciplina e, acima de tudo, paixão.

Envolvido nessa perspectiva, o PCB referiu-se poucas vezes à educação escolar. Sobre a questão, ele promoveu algumas publicações de artigos e de livros de autores que versavam sobre a educação operária, educação marxista e/ou educação na Rússia. Também publicou alguns panfletos em que centrou na crítica ao modelo vigente. Em seus programas de governo, quando se referiu à escola, pronunciou-se em defesa do acesso, assim como pela permanência de todos à educação laica. De forma geral, as críticas e as propostas pecebistas de educação escolar não iam além das reformas elencadas pelos pensadores liberais.

Porém, isto não significa que os pioneiros marxistas ignoraram a educação escolar. Para eles, a educação escolar seria um fator auxiliar na luta revolucionária, porém não era uma determinante. Acreditavam assim, que a alfabetização e a cultura escolar poderiam contribuir com a luta operária, pois, possibilitariam que os trabalhadores compreendessem e assimilassem melhor as ideias comunistas. Nesse caso, a escola era necessária, mas não imprescindível. Sobre isso, Rodolfo Coutinho (1922, p. 110) comenta que,

Como conseguir a Ação? Educando, refazendo os corações e as mentes. Esse trabalho deve ser feito por nós mesmos, com os nossos próprios recursos. Os mais capazes se não devem negar; pelo contrário por serem capazes, por isso mesmo, devem ser capazes de fazer. O capaz improdutivo é um inepto. Incapacidade é inação, indolência.

A educação é o ponto central da política revolucionária entre nós. Ou se faz educação, ou se não fará revolução. Esse movimento pró-educação deve, tanto quanto possível, compreender a alfabetização dos trabalhadores e dos seus filhos. O principal, no entanto, é a educação no verdadeiro sentido. Nesse ponto, há tudo a fazer. Grande parte da população obreira tem quase a mesma mentalidade que os escravos e avós. É pelo menos a regra nas populações agrícolas. Nas cidades, o trabalhador é um desanimado, um vencido. Quando chega a um certo conforto de vida, faz-se empreiteiro ou pequeno patrão ou operário de confiança do patrão, faz-se inimigo dos movimentos obreiros, perseguindo, denunciando como cães policiais. Os poucos camaradas, animosos e bons, depois de tentativas abortadas, perdem-se cansados e perseguidos.

[...] apoiemos sem desfalecimento as iniciativas pró-educação revolucionária; cuidemos de abrir em cada bairro operário pelo menos uma escola para ensinar a ler e a escrever; constituamos um corpo de propagandistas sinceros, conhecedores simples, para falar ao povo. (COUTINHO, 1922, p. 110).

Observa-se assim que diante do grande número de analfabetos e falta de consciência operária, o autor destacou a necessidade de se construírem escolas para ler e escrever. Entretanto, também pontuou que a formação do militante seria o foco principal da ação do Partido. Aderindo à perspectiva da vanguarda leninista, Rodolfo Coutinho defendeu que o Partido, a partir dos "capazes" , deveria alfabetizar e educar os trabalhadores e seus filhos, de forma a "despertar" a vontade revolucionária. Desta forma, formaria a consciência revolucionária, dando sentido e razão ao movimento operário. Para ele, "se a Revolução é um milagre de energia e produtividade, é a educação que faz o possível. Sem consciência não pode haver dever revolucionário” (COUTINHO, 1922, p. 111).

Semelhante a Coutinho (1922), Brandão (1978) atribuiu grande valor à consciência, a ponto de afirmar que a conscientização poderia acelerar o processo revolucionário. Porém, a conscientiza-

\footnotetext{
${ }^{20}$ Aqueles que tinham compreensão dos princípios marxistas e conseguiam traduzi-los de forma simples para os trabalhadores e iniciantes no debate político.
} 
zação era entendida como educação militante, enquanto a educação escolar era vista como apoio. Neste aspecto, Octávio Brandão escreveu que o conhecimento poderia ser uma alavanca revolucionária, no entanto, o conhecimento militante era o mais importante, visto que nesse estava a "verdade". Assim, observa-se que as teses pecebistas, de inspiração soviética, colocavam um papel fundamental na ação do Partido, vendo-o como agente formador, organizador e mobilizador do proletariado.

Entretanto, apesar de toda fé depositada na educação militante, os pecebistas não a viam como única alavanca da revolução. Nesse aspecto, é necessário considerar a perspectiva etapista pela qual liam a história no Brasil. Nesse caso, Brandão (1978) teve grande influência, na medida em que escreveu Agrarismo e industrialismo e transpôs para o Brasil o modelo etapista do desenvolvimento econômico europeu ${ }^{21}$. Acreditava-se desse modo, que o Brasil transitava do regime feudal para o capitalista e deveria ainda realizar a revolução burguesa. Assim sendo, a força revolucionária se daria primeiro para efetivar a revolução burguesa. Nessa perspectiva, a escola burguesa era entendida como uma etapa necessária. Entretanto, diferente dos escolanovistas, a educação escolar não proporcionaria a igualdade social. Sobre essa questão, Brandão (1978, p. 207) afirmava que, para atingir a igualdade e a justiça social, o "essencial" era a "revolução". Ou seja, na perspectiva de Brandão, a escola burguesa não promoveria a igualdade social. A igualdade só seria atingida por intermédio da revolução operária.

Nesse mesmo sentido, outras importantes contribuições encontram-se nas reflexões de Neves (1934). Esse teórico, na introdução do Livro Educação burguesa e educação proletária de Edwin Hoernle $^{22}$, traduzido em 1934, apontou que não há como resolver os problemas educacionais sem antes revolucionar a sociedade. Segundo ele,

pedagogos proletários revolucionários vêm nas contradições dos organismos de educação uma consequência das que corroem a sociedade capitalista, isto é, do conflito entre a super e a infraestrutura da sociedade burguesa, e procuram resolvê-las atacando diretamente a causa para que desapareça o efeito. (NEVES, 1934, p. 6).

Para ele, os problemas sociais brasileiros eram resultantes da infraestrutura social, desta forma não poderiam ser resolvidos com reformas superficiais. Nesse caso, seria necessário romper com a forma estrutural da sociedade capitalista, pondo fim na contradição entre interesses particulares e interesse coletivo. Baseado na perspectiva leninista, Neves via o Estado como gerente dos interesses da classe burguesa, portanto, suas ações eram paliativas, inclusive na educação e, apenas contribuíam para manter a ordem burguesa. Com base nesse princípio, concluiu que:

\footnotetext{
${ }^{21}$ Em 1923, Octávio Brandão traduz para o português o Manifesto Comunista de 1848, de Marx e Engels, o qual serviu de base para realizar uma interpretação da história brasileira. Essa interpretação resultou na publicação da obra Agrarismo e industrialismo em 1926, em que, Brandão chega à conclusão que, naquele momento, o Brasil ainda vivia a transição para a revolução burguesa. A tese dualista (agrarismo/industrialismo) da revolução brasileira também foi defendida por Leôncio Basbaum (militante), Nelson Werneck Sodré (ISEB - Instituto Superior de Estudos Brasileiros), e Celso Furtado (CEPAL - Comissão Econômica para a América Latina). Segundo Sodré, o processo político da chamada revolução brasileira tinha se iniciado em 1930 e foi somente na década de 50 que as condições socioeconômicas e políticas se mostraram suficientemente maduras "para permitir aquele processo de renovação a que já se convencionou chamar de Revolução Brasileira" (SODRÉ, 1978, p. 58). O grande crítico da tese dualista do PCB foi Caio Prado Jr., que, embora tenha publicado suas primeiras análises da história brasileira na década de 30, somente na década de 50 conseguiu maior expressão teórica na academia.

${ }^{22}$ Hoernle, membro do Partido Comunista da Alemanha (KPD) e colaborador da Der Abeiter-Fotograf e ideólogo da fotografia operária. Em 1929, organizou e foi inspirador do MEP alemão.
} 
o marxismo não admite a solução do problema educacional operário sem a conquista revolucionária do poder pelo proletariado, e como é esta uma tarefa dos trabalhadores adultos, principalmente, explica-se que os problemas da pedagogia marxista sejam muito pouco ventilados nos países capitalistas. (NEVES, 1934, p. 13).

Neves via a escola como um elemento social situado na superestrutura, a qual reproduzia os valores da base social burguesa. Então, a educação não poderia promover a transformação social. Desta forma, a formação militante deveria ser uma tarefa do partido operário. Uma educação que deveria ser direcionada para a revolução. Nesse aspecto, ainda destacou que a revolução deveria ser uma tarefa dos trabalhadores adultos, os quais viviam as contradições da ordem social burguesa no processo de produção. No que se refere à formação política das "crianças exploradas", afirmou que ela deveria ser realizada pelo partido do proletariado, que ensinaria a "luta pela alma da criança proletária". Ou seja,

os militantes revolucionários não se formam pela escola burguesa, mas apesar dela, graças às contradições entre educação capitalista e a sociedade, entre a formação reacionária que o capitalismo impõe e as experiências do trabalhador no processo de produção e na ordem social burguesa, uma vez que o partido do proletariado revolucionário saiba aproveitá-las na sua ação educativa. (NEVES, 1934, p. 15-16).

Desta forma, argumentou que no limite de uma sociedade capitalista "querer transformar a escola em 'instrumento para o desenvolvimento de militantes proletários'[...] era uma utopia” (NEVES, 1934, p. 15). Então, a educação militante não se faria na escola burguesa, mas longe dela.

Neves (1934) também criticou os teóricos da escola burguesa, por afirmarem que a escola proporcionaria a igualdade social. Para ele, só se atingiria a igualdade pela revolução operária. Porém, o autor admitiu que no limite da sociedade capitalista, a escola capitalista era necessária. Assim, destacou que no ensino das primeiras letras, os pedagogos burgueses haviam chegado a "métodos e processos teoricamente satisfatórios e não entram em divergências radicais com educação proletária". Nesse terreno, a pedagogia revolucionária aproveita e desenvolve as conquistas da ciência burguesa (NEVES, 1934, p. 17). Desta forma, pode-se afirmar que, a questão, para o autor não estava no pedagógico, mas no comando político ao qual a escola estava subordinada.

Outro pioneiro do pensamento marxista no Brasil foi Paschoal Lemme ${ }^{23}$, o qual é recuperado nesse trabalho, devido às suas importantes contribuições sobre o papel da escola no processo social. Sobre a questão, observa-se em depoimento posterior do autor que:

Lá pelos idos de 1933 ou 1934, recordava perfeitamente, entrando em contato com as correntes de pensamento marxista, comecei a compreender que numa sociedade dividida em classes de interesses opostos e em situação econômica nitidamente diferente não era suficiente que se pregasse uma educação gratuita, obrigatória, leiga, sem qualquer discriminação de qualquer espécie, para que todas as crianças, adolescentes e adultos, nas idades próprias, pudessem chegar às respectivas escolas e nelas permanecerem pelo tempo suficiente para tirar do ensino o melhor proveito em igualdade de condições. As desigualdades de situações econômicas, ou seja, as diferenças de classe impediam que a

\footnotetext{
${ }^{21}$ Apesar de Paschoal Lemme nunca ter se filiado ao PCB, afirmando que era "apenas um intelectual de esquerda", aqui é citado, por ser considerado pela historiografia brasileira, como um educador marxista. Simpatizante do PCB, ele contribuiu em muitas ocasiões com as atividades do Partido. Nos anos 50 , participou dos congressos mundiais de educação em Viena e em Varsóvia, organismos de notórios vínculos com a União Soviética. Veja: Buffa e Nosela (1991, p. 56) e Lemme (1988).
} 
educação se processasse dentro do principio básico do gozo desse direito, a igualdade de oportunidade para todos. E, além disso, a escola não era veículo promotor das transformações sociais que viessem proporcionar essa igualdade de oportunidades. Ou, dito de outra forma: somente numa sociedade democrática seria possível organizar uma educação verdadeiramente democrática. $E$ isso, não seria obtido pela ação da escola, mas pela atividade política, porque a escola é sempre muito mais uma mantenedora e defensora da ideologia das classes dominantes, da ordem vigente, do que promotora das transformações sociais. As transformações sociais profundas não passam pela instituição escolar [...]. Pensar que se pode fazer 'revolução' por meio da educação escolar é, no mínimo, uma ingenuidade. (LEMME, 1988, p. 24).

Para Lemme a escola é expressão da sociedade que está inserida. Assim, situada em uma sociedade marcada pelas diferenças sociais, reproduz as mesmas diferenças. Neste mesmo aspecto, destacou que ela repete a ideologia das classes dominantes, então, ela é uma instituição mais conservadora da ordem vigente do que promotora da revolução. Uma análise que também aparece no Manifesto de Reconstrução Educacional do Estado do Rio de Janeiro ${ }^{24}$, escrito em 1934. Nesse documento, seus redatores apontaram que na sociedade capitalista, os interesses da classe dominante impediam que a escola possibilitasse a democracia social:

Porque a expressão da verdade é a seguinte: a renovação escolar não pode ser realizada integralmente sem a revisão da estrutura econômica da sociedade atual, capitalista, a qual corresponde a uma consciência social incompatível com a escola científica.

Dentro dessa sociedade onde a livre concorrência na produção de mercadorias gera o problema da mão-de-obra barata, levando à exploração do trabalho escravo do homem pelo homem; dentro dessa sociedade que morre, hoje o mundo todo, no último quartel da vida que lhe resta - a democracia liberal - sob a carga já inútil dos seus milhões arrancados à miséria alheia; dentro dessa sociedade, qualquer plano puro de renovação educacional falhará, por não servir aos seus interesses supremos de dominação da massa em benefício de uma minoria parasitária e improdutiva.

E é por isso que a história educacional do Brasil se conta pelos avanços e recuos das oportunidades individualizadas; é justamente por isso que ela se expressa pela frase de Afrânio Peixoto: 'Discute-se, não se decide', isto é não se produz. É porque não houve possibilidade de produzir realmente; porque toda a possibilidade deve estar necessariamente condicionada aos interesses, em conflito, das classes em minoria que dominam e que, portanto, governam, legislam e julgam. (MANIFESTO, 1988, p. 388).

Neste aspecto, pode-se ressaltar uma diferença entre os pioneiros do pensamento marxista e os pioneiros do pensamento escolanovista no Brasil. Para os escolanovistas, a educação escolar poderia ser um elemento ativo no progresso da sociedade. Sendo assim, diretamente preocupados com a organização e o funcionamento da sociedade, defenderam que a escola era um elemento fundamental para concretização da industrialização e da democracia burguesa. Afirmaram

\footnotetext{
${ }^{24}$ O Manifesto dos Inspetores do Estado do Rio de Janeiro, cuja redação é atribuída a Paschoal Lemme e Valério Konder, o qual denominamos Manifesto de 1934, teve os seguintes signatários: Moisés Xavier de Araújo (Inspetor Geral do Ensino); Fábio Crissiuna de Oliveira Figueiredo, Oscar Edivaldo Portocarreiro, Waldemar Dias Paixão (Inspetores de Ensino Normal); Abelardo Coimbra Bueno, Francisco Mendes de Oliveira Castro, Jorge Barata, Milton Paranhos Fontenelle, Paschoal Lemme, Paulo Celso de Almeida Moutinho, Pedro Gouveia Filho, Roberto Pessoa, Valério Regis Konder (Inspetores de Ensino Primário e Profissional).

${ }^{25}$ Os escolanovistas fundamentavam suas análises, também, na perspectiva de sociedade divulgada por Durkheim. Nesse sentido, acreditavam que a sociedade, em um processo evolutivo e gradual, construía novas potencialidades e avanços que, naturalmente, produziam melhorias de vida, devendo a educação criar um homem adequado a esse processo.
} 
que a escola deveria acompanhar as mudanças que já ocorriam na sociedade e oferecer qualificação necessária para que todos, independente da estrutura econômica e cultural da família, tivessem oportunidades iguais para concorrerem na produção.

Dessa forma, acreditavam que a escola poderia atenuar as diferenças sociais bem como oferecer a formação necessária para o mercado de trabalho e para as funções de cidadão. Nesta perspectiva, esperavam que a escola, naquele momento, poderia reconstruir e regenerar a sociedade e/ou a cultura brasileira, com a possibilidade de romper com o "atraso" e avançar no processo de industrialização e de democracia que já ocorria em nações mais desenvolvidas. Assim, compreendiam a escola como obrigação e direito de todos.

Os marxistas, entretanto, a partir do pressuposto que a sociedade capitalista é, por sua natureza, estruturada nas diferenças sociais, afirmavam que a escola não poderia promover a equalização social. Desta forma, para os pioneiros do pensamento marxista, o elemento ativo da transformação social estava no desenvolvimento histórico da produção que poderia ser acelerado pela mobilização da classe operária. Neste sentido, atribuíam grande importância à formação do militante por intermédio do Partido. Ao se referirem à escola, destacavam-na como necessária e não acreditavam que ela possibilitaria a igualdade social. Para eles, a igualdade se faria somente pela revolução operária. Neste caso, não depositavam na escola qualquer papel ativo no processo revolucionário.

Porém, se por um lado havia divergência crucial no que se refere ao papel da escola no processo de transformação e de construção da igualdade social, por outro, verifica-se que as divergências não eram cruciais, quando se referiam ao projeto de reforma educacional. Ao contrário, os marxistas defendiam e achavam necessários alguns aspectos da reforma escolar proposta pelos escolanovista, como pode se verificar em registros, nos documentos do PCB e nos textos escritos pelos pioneiros marxistas.

Em consonância com as solicitações escolanovistas, o PCB, em seus Programas de Governo, registrou que o Estado deveria ampliar o número de escolas, subsidiar o aluno e pagar melhor os professores. Para o partido, era preciso ampliar e garantir o acesso de todos à escola. Nesse sentido, Brandão (1978) escreveu que a reforma escolar deveria contribuir para romper com o modelo de educação aristocrático, elitista e baseado na memorização. Em termos pedagógicos, destacou que no modelo de ensino brasileiro, a "criança não aprende a pensar e ter mentalidade própria. O indivíduo é transformado em autômato, vítima da mais grosseira memorização". No mesmo sentido, referindo-se ao conteúdo, alegou que ele era baseado em "mentiras religiosas, patrioteiras e capitalistas" (BRANDÃO, 1978, p. 206-207).

Sobre a questão, os redatores do Manifesto de 1934, consideraram que a reforma era imprescindível e condizente ao processo de renovação que estava ocorrendo no Brasil e em outras partes do mundo. Muito próximos àquilo que os escolanovistas defendiam, eles apontaram para a necessidade de reformular os princípios pedagógicos, tornando-os mais científicos, ativos e menos rígidos. Também defenderam a constituição de uma política para a educação e, semeIhantes às justificativas apresentadas pelos escolanovistas, criticaram o Estado, afirmando que ele era omisso em relação à educação popular. Neste caso, recuperaram a história do ensino brasileiro e, entre inúmeros destaques, registraram que a cúpula republicana buscou, nos limites de seus interesses, o reajustamento econômico, mas, em matéria de "educação popular, a cegueira, correlativa a essa situação, continuou" (LEMME, 1988, p. 358). Ou seja, denunciaram a ausência de uma política educacional para o Brasil.

Em termos pedagógicos, pode-se afirmar que os pioneiros do pensamento marxista não dispunham de qualquer proposta própria. Em geral, suas posições se firmavam na defesa da escola pública e da necessidade de se introduzir a ciência moderna na educação, ao passo que critica- 
vam a política do governo capitalista, o conteúdo religioso e a pedagogia da memorização. Neste aspecto, se aproximavam das teses escolanovistas, pois as entendiam como as mais desenvolvidas. Logo, compreendiam que a escolarização da população deveria ser impulsionada. Para eles, essa era uma necessidade social.

\section{4 | CONSIDERAÇÕES FINAIS}

No que se refere à transformação da sociedade, diferente dos escolanovistas que depositavam na escola a esperança de equalização social, os pecebistas não atribuíam à escola qualquer papel direto. Para eles, a igualdade se faria somente via Revolução Operária, conduzida, organizada e mobilizada pelo Partido.

Nesse aspecto, ancorados pelas perspectivas da III Internacional Comunista, apostavam seus esforços na educação militante realizada por intermédio do Partido. Para eles, a escola conseguiria ensinar a consciência comunista apenas depois do fim da sociedade capitalista. Entretanto, no limite daquele contexto, os pioneiros marxistas viam a escola pública burguesa como necessária, portanto, não se opuseram aos pioneiros escolanovistas, mas, pelo contrário, foram coadjuvantes dos escolanovistas, na sua proposta de reforma educacional.

A postura dos pioneiros marxistas parece estranha quando é comparada às teses atuais do pensamento marxistas que denunciam o pensamento escolanovista como forma de recompor e fortalecer a hegemonia burguesa. Diante de tal divergência, o que afirmar sobre o pensamento marxista? Pode-se afirmar que há um erro de leitura nesse pensamento? Para responder tais questões destaca-se que, de fato, na década de 1930, outra exigência educacional se impunha com a reorganização da produção e da política capitalista. Sendo assim, naquele período, a sociedade brasileira intensificou o debate sobre seu processo de ensino, tanto no que se referia às necessidades do processo de trabalho, especialmente ao uso da ciência e da máquina, quanto no que se referia aos novos desafios postos pela expansão da política populista.

Apesar das divergências ideológicas no que se refere ao papel da escola e ao futuro da sociedade, marxistas e escolanovistas se uniram, visto que a ampliação do sistema de ensino e a reforma pedagógica eram exigências do período.

Quanto ao pensamento marxista, longe de desmerecer a luta dos pioneiros marxistas ou querer julgar a leitura que os marxistas atuais fazem do passado educacional brasileiro, é necessário destacar que existe, nesse pensamento, uma distinção tática sobre a escola no processo de transformação social, a qual precisa ser entendida.

Sem o desmerecimento das significativas contribuições marxistas que permitem ampliar nossa compreensão sobre a estrutura organizacional do sistema de ensino, é necessário destacar que a leitura marxista atual possui como fundamento as teses Gramscianas, divulgadas pelos cursos de educação universitários, após a década de 1980. Nesse sentido, fica fortalecido o ideal de alargar o senso crítico por intermédio da educação escolar e realizar um ensino comprometido com a transformação da sociedade. Uma mudança de perspectiva educacional que lança para dentro da escola um espaço de luta que antes era exclusividade do partido. No meio acadêmico, se fortalece assim, a tese de que a construção de uma sociedade mais igualitária não depende unicamente de uma revolução drástica no campo econômico-social, mas também de uma revolução ideológica ${ }^{26}$. Nesta perspectiva, alguns marxistas atuais voltam ao passado educacional brasileiro

\footnotetext{
${ }^{24}$ Segundo Dore (2006), as idéias de Gramsci contribuíram para se contrapor à teoria da escola como aparelho ideológico do Estado de Louis Althusser, o que resultou na defesa de uma pedagogia comprometida com os ideais de transformação da sociedade.
} 
e evidenciam a luta ideológica na educação, a qual, muitas vezes é camuflada em nome da "felicidade geral da nação".

No que se refere aos pioneiros do pensamento marxista, antes de julgá-los, é necessário destacar que sua posição perante a proposta de reforma escolanovistas pode ser explicada pela sua perspectiva histórica. Naquele momento, as teses pecebistas eram fundamentadas na tradução das obras marxista-leninistas, as quais divulgavam a dinâmica produtiva européia e a organização da luta operária pelo partido. Nesse sentido, com base no processo histórico europeu, os pecebistas analisaram a história do Brasil, traçaram comparações e chegaram à conclusão de que o Brasil estava "atrasado", pois ainda vivia a transição do feudalismo para o capitalismo. Para eles, no setor produtivo agrário, ainda resistia o domínio do poder feudal.

Acreditavam que deveriam unir forças com a pequena burguesia para consolidar o processo de industrialização e a constituição do trabalho assalariado. Nesta perspectiva etapista e bipolar da história brasileira, acreditavam que o movimento operário, primeiramente, deveria vencer a etapa da revolução burguesa no Brasil, para somente depois seguir no propósito de promover a revolução operária. No limite de suas leituras sobre o contexto, viam a escola burguesa como uma etapa necessária. Fato que explica sua postura perante as propostas de reforma lideradas pelos escolanovistas.

Em síntese, mais do que dividir o pensamento educacional e ou as correntes teóricas em certos ou errados, deve-se verificar que as perspectivas educacionais são construídas de acordo com as concepções de história. 
PIONEIROS DO MARXISMO | Aparecida Favoreto

\section{Referências}

BRANDÃO, O. Combates e batalhas (memórias). São Paulo: Editora Alfa Ômega, 1978. v. 1.

BUFFA, E.; NOSELA, P. Educação negada: introdução ao estudo da educação brasileira. São Paulo: Cortez, 1991. (Coleção biblioteca da educação).

COUTINHO, R. O dever revolucionário. Movimento Comunista. São Paulo: CEDEM, 1922.

DEWEY. J. Democracia e educação. São Paulo: Companhia Editora Nacional, 1959.

DURKHEIM, E. Educação e sociologia. Petrópolis, RJ: Vozes, 2012.

DORE, R. Gramsci e o debate sobre a escola pública no Brasil. Cadernos CEDES, Campinas, v. 26, n. 70, p. 329-352, set./dez. 2006.

GANDINI, R. Tecnocracia, capitalismo e educação em Anísio Teixeira (1930 - 1935). Rio de Janeiro: Civilização Brasileira, 1980.

GHIRALDELLI JÚNIOR, P. Pedagogia e luta de classes no Brasil (1930-1937). 1989. Tese (Doutorado em Educação)- Pontifícia Universidade Católica de São Paulo, São Paulo, 1989.

LEMME, P. Memórias. São Paulo: Cortez; Brasília: INEP, 1988. v. 4.
MANIFESTO dos inspetores de ensino do Estado do Rio de Janeiro (1934). In: LEMME, P. Memórias. São Paulo: Cortez; Brasília: INEP, 1988. v. 4.

MANIFESTO dos pioneiros da educação nova. Revista Brasileira de Estudos Pedagógicos, n. 70, p. 108-127, 1960.

NEVES, J. Introdução. In: HOERNLE, E. Educação burguesa e educação proletária. São Paulo: Unitas, 1934.

RIBEIRO, M. L. S. História da educação brasileira: a organização escolar. 15. ed. Campinas: Autores Associados, 1998. (Coleção memória e educação).

SAES, D. A. M. de. Classe média e escola capitalista. Revista Crítica Marxista, Campinas: Revan, n. 21, p. 97-112, nov. 2005.

SAVIANI, D. Escola e democracia. São Paulo: Cortez; Autores Associados, 1983.

SODRÉ, N. W. Introdução à revolução brasileira. São Paulo: LECH, 1978.

WARDE, M. J. Liberalismo e educação. 1984. Tese (Doutorado em Educação)- Pontifícia Universidade Católica de São Paulo, São Paulo, 1984. 